\title{
Testigos de la profanación. Interrogantes sobre los conversos españoles ante la destrucción de cementerios judíos tras la Expulsión de 1492
}

Recibido: 28/03/20. Aceptado: 17/06/20.

\begin{abstract}
Resumen
Las conversiones de judíos producidas en ocasión de promulgarse el edicto de expulsión de 1492 fueron radicalmente distintas a las anteriores: se trataba de un escenario donde ya no habría ex-correligionarios ni sinagogas, tampoco ningún símbolo que tuviera que ver con su anterior religión. La historiografía ha debatido largamente respecto de la situación de los judeoconversos, con posturas que en sus extremos defienden la asimilación completa o bien una resistencia absoluta a la integración. Sin embargo, escasa atención se ha prestado a la incidencia que en dicho proceso pudo alcanzar la destrucción de su entorno material y simbólico, portador de una singular carga afectiva. Únicamente esa generación fue testigo de la eliminación de los que habían sido sus lugares sagrados. Con el afán de borrar todo rastro del judaísmo, no solo se hicieron desaparecer las sinagogas, sino también los cementerios. En el presente trabajo se describen y analizan la sistemática profanación y destrucción de sepulturas, con el fin de interrogarse hasta qué punto tales hechos pudieron incidir en el proceso de (re)integración de los judeoconversos castellanos.
\end{abstract}

Palabras clave: conversos, cementerios judíos, profanación.

\section{Witnesses of the Profanation: Questions about Spanish Converts facing the destruction of the Jewish's Cemeteries after the Expul- sion of 1492}

\begin{abstract}
The conversion of Jews after the Edict of Expulsion of 1492 was completely different from the previous ones. In this case, Jews found out that there were no more ex-coreligionists, synagogues or symbols to link with their previous religion. Historiography has largely debated about the situation of the converted-Jews, counting a wide range of opinions from those who advocate for their total assimilation, to those who propose their absolute resistance to integration. However, little attention has been paid, in that
\end{abstract}


process, to the impact that the destruction of their material and symbolic environment had, considering the emotional charge these spaces embodied. As an example, cemeteries were destroyed in order to remove any sign of Judaism. Only the generation of converts after the Edict of Expulsion witnessed the suppression of those sacred places. In the following pages, we will describe and analyse the systematic profanation and destruction of graves, with the purpose of measuring to what extent these actions could have influenced the process of (re)integration of the Spanish judeoconversos.

Keywords: converts, Jewish's cemeteries, profanation.

\section{Introducción}

Los judíos pasan en sus cementerios los últimos días de su residencia en España. Delante de las lápidas de sus mayores se despiden de Iberia. (...) algunos judíos tienen que ser obligados por la fuerza a separarse de las tumbas.

Valeriu Marcu. ${ }^{2}$

El autor de las palabras del epígrafe, en su obra publicada por vez primera en 1934, interpretaba la expulsión de los reinos hispánicos como uno de los hechos más trágicos que había atravesado la comunidad judía en su historia. Valeriu Marcu, historiador y ensayista de origen rumano radicado desde muy joven en Alemania, probablemente nunca imaginó mientras escribía esas páginas hasta qué punto las impresiones allí vertidas quedarían minimizadas ante la magnitud de los acontecimientos que se sucederían en los años siguientes. En 1940, Marcu alcanzaría a emigrar a Estados Unidos, donde falleció al poco tiempo, a la temprana edad de 43 años. Hemos considerado relevante recuperar ese instante de su evocación, pues transmite la significancia que el destierro de los reinos hispánicos ordenado en 1492 tenía en la memoria del pueblo judío hasta las vísperas mismas de la Shoah-habiendo transitado otras expulsiones e incluso los pogroms del siglo XIX-. Las frases que reproducimos relatan escenas desgarradoras; escenas que seguramente se habrán repetido en distintas ciudades castellanas y que hacen referencia a la despedida de aquellos que habían asumido la decisión de partir. En el presente trabajo, sin embargo, hemos de centrarnos en las vivencias, sin dudas también dolorosas, que hubieron de padecer los judíos y judías que en esas circunstancias terminantes optaron por el bautismo cristiano -ya fuera antes de la fecha límite impuesta o bien al regresar, luego de un período en el exilio-.

Las conversiones de judíos que tuvieron lugar en tal contexto no son comparables con las que, aun masivas, se habían producido con anterioridad. Quienes se bautizaron en esa coyuntura lo hicieron ante una realidad radicalmente distinta: en el nuevo escenario ya no habría ex correligionarios ni sinagogas, tampoco ningún símbolo que tuviera que ver con su religión precedente. Asumir la conversión en esos momentos implicaba no solo aceptar la incorporación a la comunidad cristiana sino también resignarse a vivir en una parte del mundo donde, al menos formalmente, el judaísmo se hallaba condenado a la extinción.

1 Abreviaturas: $\mathrm{ACP}=$ Archivo Catedralicio de Plasencia; AGS = Archivo General de Simancas; ARCHV = Archivo de la Real Chancillería de Valladolid; RE = Registro de Ejecutorias; RGS = Registro General del Sello.

Una versión muy preliminar de esta investigación fue presentada en el XII Coloquio Internacional de Historiografía Europea y IX Jornadas de Estudios sobre la Modernidad Clásica (Mar del Plata, 2017). Agradezco a María Inés Carzolio los valiosos comentarios brindados en esa oportunidad. Asimismo, quiero agradecer a los evaluadores anónimos de la revista por las críticas enriquecedoras y las sugerencias oportunas.

2 La cita pertenece a su obra La expulsión de los judíos de España, publicada por primera vez en 1934 (Marcu, 2012, p. 138). 
La historiografía ha debatido largamente respecto de la situación de los judeoconversos, ${ }^{3}$ en un amplio abanico que en sus posiciones extremas defiende la asimilación completa, por un lado, o bien una resistencia absoluta a la integración, por el otro. ${ }^{4}$ Se trata de un proceso que ha sido analizado casi siempre bajo el prisma de la aceptación o el rechazo en un sentido cultural, religioso e, incluso, estrictamente doctrinal o litúrgico. Sin embargo, escasa atención se ha prestado a la incidencia que en dicho proceso pudo alcanzar la destrucción o mutación rotunda de su entorno material y simbólico, portador de una singular carga afectiva. Únicamente esa generación de judeoconversos fue testigo de la desaparición, del derrumbe o de la resignificación de sus lugares sagrados, no solo de las sinagogas, como es evidente, sino también de los cementerios, cuyas tumbas fueron violadas con el propósito de borrar todo rastro del judaísmo. Es precisamente sobre este último aspecto que concentraremos nuestra atención, pues si bien existen excelentes investigaciones sobre los restos materiales de Sefarad, no se ha ahondado en el impacto que tales destrucciones pudieron tener en los contemporáneos. Basándonos en una profusa documentación de procedencia judicial ${ }^{5}$-a la que se suman testamentos y documentos recuperados a partir de otras publicaciones- esta propuesta intenta poner de relieve tales profanaciones, con el convencimiento de que, por su naturaleza, hubieron de afectar emocionalmente a los recién convertidos, pudiendo incluso influir en el de por sí complejo trance de su (re)integración ${ }^{6}$ social en los años posteriores al edicto de expulsión. Así pues, tras referirnos a las conversiones derivadas de la orden de destierro y a lo sucedido con los bienes pertenecientes a judíos (en especial, los bienes comunales), describiremos sintéticamente las ceremonias ante la muerte, las sepulturas y los enterramientos judíos para luego detenernos en la destrucción de los cementerios e interrogarnos sobre las consecuencias emocionales (y sociales) que estos hechos provocaron en los recién convertidos.

\section{La particularidad de las conversiones en el contexto de la expulsión}

Las conversiones del judaísmo al cristianismo -e incluso también en sentido inverso ${ }^{-}$ se habían producido a lo largo de la historia de ambas religiones, alcanzando niveles elevados en momentos de persecuciones o de prédicas intensivas. En la Península

3 La bibliografía sobre judeoconversos, como se sabe, es amplísima; por razones de espacio, nos limitaremos a mencionar solamente algunos de los autores que se han dedicado al tema, consignando, a modo ilustrativo, una obra de la prolífica producción de cada uno: Alcalá (1995); Beinart (1983); Benito Ruano (2001); Caro Baroja (19862000); Contreras (1992); Dedieu (1992); Domínguez Ortiz (1992); Égido (1997); García Cárcel (1980); Gitlitz (2003); Haliczer (1997); Huerga Criado (2000); Kamen (1985); Kaplan (1996); López Vela (2008); Kriegel (2002); Netanyahu (2002); Perez (2007); Pulido Serrano (2002); Rábade Obradó (1999); Révah (1995); Roth (1990); Wachtel (2001); Yerushalmi (1998).

4 A modo de ejemplo de estas posturas extremas, podemos mencionar, por un lado, a Haim Beinart (1983), quien basándose en documentación inquisitorial ha afirmado que la mayoría de los conversos intentaron continuar con la observancia de los preceptos judíos y, por otro, a Benzion Netanyahu (2002), que ha sostenido con firmeza -al menos desde la década de 1950 y ciñéndose a fuentes hebreas- que los conversos se hallaban perfectamente integrados a la sociedad cristiana.

5 Se trata de pleitos entre partes o bien de demandas, denuncias o peticiones presentadas ante los jueces de Consejo Real (tratadas ya sea por vía procesal o por vía expeditiva) o ante alcaldes u oidores de la Real Audiencia y Chancillería de Valladolid. Por lo tanto, la documentación judicial estudiada se limita al ámbito jurisdiccional de ambas instituciones.

6 Decimos re-integración (y remarcamos el concepto) pues, tal como sostenemos desde hace tiempo -en oposición a lo que afirman otras posturas- consideramos que, pese a las medidas segregacionistas y las expresiones de violencia, los judíos se hallaban integrados en la sociedad mayoritaria cristiana, en especial en lo concerniente a los aspectos económicos y políticos. Para ampliar, véase Caselli (2008 y 2016).

7 Se conocen sobre todo las conversiones de eclesiásticos, quienes al pasar a predicar en favor del judaísmo, han dejado testimonio de su conversión, lo cual no significa, claro está, que fueran las únicas. En el siglo IX, Bodón, diácono de palacio de Luis el Piadoso, se trasladó a la Península lbérica y se convirtió al judaísmo, tomando el nombre de Eleazar. A comienzos del siglo XI, abandonó el cristianismo el capellán del duque Conradino. A mediados del mismo siglo hizo lo propio un sacerdote, cuyo relato autobiográfico anónimo se ha conservado. En los primeros años del siglo XII mudaba de religión el presbítero normando Juan de Oppido, quien al convertirse tomó el nombre de Obadías (Momigliano, 1996, p. 367 y ss.; Lara Olmo, 1998, pp. 133-159). Por nuestra parte, hemos hallado las referencias de la conversión al judaísmo de un cristiano, cuyo hijo llegaría a ser rabino. Cfr. ARCHV. RE. 1489.26.24. 
Ibérica, se conocieron desde épocas muy tempranas, ${ }^{8}$ incrementándose a partir del siglo XIII, en especial debido a las prédicas de las órdenes religiosas. Sin embargo, no habían llegado a la envergadura de las registradas entre finales del siglo XIV y comienzos del XV, período signado por persecuciones violentas -en especial los pogroms de 1391-y por arengas de fervientes predicadores -en ocasiones, acompañadas de disputas teológicas?-, las que, sembrando terror e inseguridad, condujeron a infinidad de judíos a las pilas bautismales. No obstante la masividad del fenómeno, estas conversiones se desarrollaron en contextos que, aunque siempre bajo la impronta de una fuerte adversidad antijudía, eran radicalmente distintos. Los cristianos nuevos cambiaron su religión y, con ella, su condición social y su estatus jurídico; sin embargo, continuaron viviendo en sus mismas casas, rodeados por sus ex correligionarios, que no pocas veces eran familiares y amigos, y por los símbolos de su fe anterior. A esta cercanía se la juzgaría culpable de la judaización de muchos conversos. ${ }^{10}$ Para evitar, precisamente, que los judíos "tentaran" a los nuevos cristianos hacia la práctica de ritos mosaicos, en 1480 se recuperó una ley de $1412^{11}$ que disponía la separación de judíos y judías en barrios cerrados. Y sería ese mismo espíritu segregacionista el que sustentaría en 1483 la expulsión parcial de Andalucía y, en 1492, la decisión del destierro definitivo de los reinos hispánicos. ${ }^{12}$

No hay acuerdo acerca del número de judíos que habitaban en el reino de Castilla, como tampoco la hay sobre cuántos emprendieron el camino del exilio y, por ende, cuántos se convirtieron en aquel momento. ${ }^{13}$ Por otra parte, aunque son situaciones difíciles de discernir, es preciso considerar a aquellos que regresaron. En este sentido, las fuentes judiciales, si bien no facultan para hablar de cifras taxativas, echan luz sobre un aspecto poco trabajado, ${ }^{14}$ permitiendo reconstruir los derroteros de numerosas familias (Caselli, 2011 y 2017a). De todas maneras, más allá de los guarismos, interesa aquí insistir sobre las vivencias de quienes aceptaron el bautismo cristiano en esa coyuntura, ${ }^{15}$ prestar atención a esa generación que sin dudas quedó marcada por experiencias traumáticas: además de atravesar la angustia de la conversión para poder permanecer en su tierra, vio "partir a familiares o amigos a los que perdía para siempre" (Gitlitz, 2003, p. 54), fue testigo involuntario de la destrucción de sinagogas, del desmantelamiento de cementerios, de la profanación absoluta de las sepulturas, de la eliminación, en definitiva, de todo rastro del judaísmo.

8 La primera conversión masiva que se registra remite a Mahón en el siglo V (González Salinero, 2000, pp. 232-239). También existieron otras conversiones masivas que tuvieron lugar bajo la presión ejercida durante el período visigodo (Suárez Bilbao, 2000, p. 47).

9 Destaca, en particular, la prédica de San Vicente Ferrer y la Disputa de Tortosa, que culminaría en 1414 (Pacios López, 1957).

10 Así lo reza el propio edicto de expulsión: “...el gran daño que a los cristianos se ha seguido e sigue de la participación conversación comunicación que han tenido e tienen con los judíos los cuales se prueban que procuran siempre por cuantas vías e maneras pueden de subvertir e sustraer de nuestra Santa Fe Católica a los fieles cristianos (...) instruyéndolos en las ceremonias e observancias de su ley..." (AGS. Patronato Real. Legajo 28 Doc. 6).

11 Nos referimos a las denominadas “Leyes de Ayllón”, promulgadas por la regente Catalina de Lancaster, durante la minoridad de Juan II, a instancias de Vicente Ferrer y de Pablo de Santa María (Pérez, 1993, pp. 59-60).

12 Tanto las leyes de apartamiento como la expulsión de Andalucía fueron invocadas en el edicto de 1492 como políticas tendientes a remediar un contacto considerado pernicioso, cuyo propósito, según allí mismo se expresaba, había fracasado (AGS. Patronato Real. Legajo 28 Doc. 6).

13 Las diferencias se originan en las mismas crónicas contemporáneas: para Andrés Bernáldez no llegaban a 100.000. Él calculaba unos 83.000 que habían salido hacia Portugal y el norte de África, más unos 12.00o hacia Navarra. Por su parte, Isaac Abravanel hablaba de 300.00o. En la historiografía tampoco hay coincidencias: para Yitzhak Baer (1998) fueron cerca de 170.000; número que Haim Beinart (1992) hace trepar a 200.000. Por su lado, Henry Kamen (1988) reduce la cifra de exiliados a 50.00o. En tanto que Luis Suárez Fernández (1964 y 1980) y Miguel A. Ladero Quesada (1995) proponen moderar esa cifra. Basándose principalmente en los repartos fiscales y otras constataciones, estos autores estiman que vivían en Castilla entre 80.000 (según los repartos) y 100.000 judíos (según otras fuentes); de modo que habría que reducir considerablemente el número estimado de quienes dejaron el Reino en 1492.

14 Entre quienes se han dedicado al tema, se destacan los trabajos de Haim Beinart (1995 y 2002) y de Enrique Cantera Montenegro (1979).

${ }_{15}$ Cabe destacar que la mayoría de las conversiones se produjeron cuando se hallaba próximo a vencer el plazo para salir del reino (Rábade Obradó, 1999). 


\section{Los bienes pertenecientes a judíos}

Tal como se acostumbraba, el edicto se pregonó en cada pueblo; las crónicas de la época subrayan el impacto que provocó semejante noticia. ${ }^{16} \mathrm{La}$ conmoción es corroborada, asimismo, por la documentación de procedencia judicial. En los meses que mediaron entre los primeros días de abril, cuando se difundió la noticia, y el 31 de julio, fecha límite fijada para la salida del reino, se produjo una especie de eclosión de denuncias y demandas judiciales (Caselli, 2016, pp. 241-255). En ese reducido margen, se vieron obligados a decidir qué hacer, qué llevar y cómo hacerlo. Los judíos se hallaban comprendidos en las generales de la ley, por ende no podían sacar del reino "cosas vedadas" (en especial, dinero y metales preciosos, en cualquiera de sus formas); se les permitía vender sus bienes -muebles e inmuebles- pero el producto de esa venta solo podía ser sacado en mercancías autorizadas o en letras de cambio. Tal contexto se tradujo en un caldo de cultivo propicio para aprovechadores y oportunistas que supieron obtener ventajas de esa situación límite. Así, casas, viñas, huertas, molinos u otras propiedades fueron en su mayoría malvendidas por menos de la mitad o la tercera parte de su "justo precio" -en términos de la época- muchas de las cuales constan en los reclamos presentados ante la justicia por judías y judíos que retornaron bautizados (Caselli, 2011).

Los contratos entre particulares en ese momento vigentes, se tratara de préstamos o de ventas a plazo, debían ser liquidados, fuera cual fuese la fecha prevista para su cancelación. Los acuerdos con vencimiento posterior al 31 de julio se traspasaron a terceros, quienes por lo general adquirieron el derecho a cobrar obteniendo ventajas considerables. En cambio, aquellos cuya data de extinción había sido pactada para esos meses se tornaron prácticamente incobrables. No es difícil imaginar el escaso, por no decir nulo, poder de persuasión que tenía un acreedor judío bajo tales circunstancias. Por el contrario, los judíos endeudados con cristianos se volvieron para estos últimos un motivo de preocupación. Las solicitudes de amparo o de medidas cautelares presentadas ante la justicia en ese tiempo son cuantiosas. En casi todas ellas se exigían garantías "llanas e abonadas [pero] cristianas" 17 o bien que se mantuviera en prisión al deudor ${ }^{18}$ hasta que hiciese efectivo el pago para evitar que, atendiendo al mandamiento real, se fuera del reino sin saldar su deuda. La contrapartida eran las denuncias de judíos que daban cuenta de situaciones abusivas o de resistencia al pago de deudas ya vencidas. De allí el auge de pleitos al que hacíamos referencia.

En ese contexto, los Reyes emitieron diversas pragmáticas tendientes a controlar, de alguna manera, los abusos. Sin embargo, a juzgar por las denuncias y los conflictos originados, podría afirmarse que poco lograron. Se dispuso la anulación de los contratos pendientes entre judíos y cristianos, quedando supeditados a la evaluación y posterior decisión del Consejo Real. ${ }^{19} \mathrm{Al}$ mismo tiempo, se designaron "jueces ejecutores de bienes de judíos" con facultades para liquidar contratos en los lugares donde habían sido, al tal efecto, designados. Pero al mismo tiempo a los judíos se les había permitido vender sus bienes muebles e inmuebles o traspasar sus derechos a cobrar. Huelga señalar que la cantidad de litigios suscitados como consecuencia de tales indefiniciones y solapamientos fue considerable. Quienes habían adquirido derechos a cobrar a menudo se encontraban con que las deudas eran irrealizables debido a que los contratos sobre los cuales

16 Véase, por ejemplo, las crónicas de Yosef ben Saddiq (1992) y de Abraham bar Selomoh (1992). También la conocida obra de Ha-Kohen (1989).

17 Véase un caso concreto en ARCHV. RE. 1494.78.3.

18 Un ejemplo puede ser encontrado en ARCHV. RE. 1492.50.5.

19 La primera orden fue dada en Zaragoza, con fecha 10 de septiembre de 1492 y reiterada luego en noviembre de ese mismo año y en enero del año siguiente (AGS. RGS. 1492.11.227; AGS. RGS. 1493.01.175). 
se fundaban habían sido puestos bajo la órbita del Consejo Real, hallándose en suspenso, o bien, objetados por "logro y usura". Otro tanto sucedía con los bienes raíces, pasibles de recibir diversos destinos. Por ejemplo, si una casa, legalmente vendida por su dueño judío a un cristiano, no era ocupada de inmediato, podía ser considerada como bien vacante y usurpada, o bien confiscada por un juez ejecutor y asignada a otra persona o aplicada a la Cámara Real, desde donde era posible que la hicieran objeto de una merced. ${ }^{20}$

El mismo desorden apreciable en el destino de los inmuebles particulares se constata en aquellos pertenecientes a la comunidad. En casos excepcionales, algunas aljamas consiguieron malvender sus bienes comunales, como veremos más adelante, pero esto no fue lo que primó: por el contrario, dichas propiedades que formalmente habían sido puestas bajo la órbita del "fisco o Cámara Real", en la práctica, quedaron supeditadas a los abusos y las especulaciones entre cristianos. Tomemos un ejemplo: un fraile de la "casa de Sanctispiritus" compró a un mercader una de las sinagogas de Burgos por una cifra irrisoria, tras lo cual la consagró, bajo la anuencia del obispo y del cabildo catedralicio de la ciudad. Tiempo después, se presentó el recaudador de bienes de judíos, exigiendo que le fuera entregada pues en tanto bien comunal pertenecía a Sus Majestades. El fraile se negaba a desocuparla, argumentando no solo que, al haber sido consagrada, era un sitio inviolable, sino especialmente amparándose en el hecho de que él la había adquirido por vía legal, lo que demostraba exhibiendo los títulos correspondientes. Mientras tanto, demandó al mercader, acusándolo de efectuar una venta viciada. El reclamo dio lugar a un extenso pleito que llegó por vía de apelación a la Real Audiencia de Valladolid, gracias al cual nos enteramos de que el mercader, con acuerdo del corregidor, había literalmente ocupado la sinagoga -e incluso en el documento se describe cómo se procedía en un acto de ocupación- lo que explica que la vendiera a un precio tan bajo. ${ }^{21}$ En otro lugar (Caselli, 2016, pp. 280-287) hemos analizado de manera pormenorizada el caso, que es largo y con visos de escándalo -el mercader acusó al fraile de sodomía-y que aquí traemos a colación con el mero fin de ilustrar las complicaciones y los litigios surgidos entre cristianos por bienes que habían pertenecido a judíos.

\section{Ritual funerario y sepulturas en la cultura sefardí}

Como señaló hace ya tiempo Philippe Ariès, en la Antigüedad los sitios de enterramiento eran percibidos como una frontera con otro mundo, se honraban las sepulturas, pero debían hallarse separadas del mundo de los vivos, de allí la prohibición de los entierros in urbi. Con el cristianismo y el culto a los mártires -que originalmente se sepultaban extramuros- tal separación se fue perdiendo y basílicas y catedrales comenzaron a disponer de sitios sepulcrales. Los deseos de los devotos de ser inhumados junto a los santos transformaron, paulatinamente, a las iglesias en lugares de enterramiento y fue así como los cementerios penetraron en el corazón de las ciudades (Ariès, 2017, pp. 34-37). En el universo judío medieval, en cambio, se mantuvo el apartamiento y una neta distinción. De hecho, a las necrópolis se las solía denominar bet olam (casa de la eternidad) para distinguirlas del espacio de la judería. Según el Talmud, los enterramientos debían realizarse en tierra virgen, no solo lejos de la sinagoga, sino distantes también - por al menos cincuenta codos- de cualquier núcleo poblacional (Motis, 1998, p. 195). No obstante y a pesar de encontrarse extramuros, tampoco se emplazaban

20 Hemos analizado y ejemplificado estas diversas situaciones en Caselli (2016, pp. 241-287).

21 ARCHV. RE. 1504.196.8. 
en lugares demasiado apartados de la judería y, en lo posible, se evitaba que barrios cristianos quedaran en el medio, para que los cortejos fúnebres judíos, en su tránsito, no tuvieran que atravesarlos (Cantera, 1998, pp. 168-169).

Pero, antes de continuar con la descripción de los cementerios, repasemos brevemente algunos detalles rituales. Comencemos por recordar que la creencia en una vida ultraterrena hacía que, ante la inminencia de la muerte, se observaran minuciosamente ciertos ritos y ceremonias, en la fe de que su cumplimiento ayudaba en ese tránsito hacia el más allá. Era habitual que, en las últimas horas de su vida, judías y judíos fueran acompañados por familiares y amigos, pues correspondía evitar que murieran en soledad (Karo, 1956, p. 266). También debía procurarse que el moribundo pronunciara palabras de arrepentimiento y confesión (Grinvald, 2006, p. 536). Tan pronto como se producía el fallecimiento, se cerraban los ojos del difunto y se procedía luego al lavado cuidadoso del cadáver, para su purificación, en una ceremonia donde se recitaban salmos y plegarias. Tras el aseo mortuorio, se amortajaba el cadáver y se lo envolvía con un lienzo blanco. Es importante destacar que, para que hubiera plena igualdad ante la muerte, no se utilizaban adornos suntuosos ni alhajas de oro y plata, por lo que prácticamente no se han conservado elementos de ajuar (Cantera, 2015, pp. 106-110). Según el Shuljan Aruj, "es costumbre arraigada rasgar las ropas con motivo de la pérdida de un pariente cercano (...) lo mejor es [hacerlo] cuando la pena es todavía muy intensa, antes de la clausura del ataúd" (Karo, 1956, p. 266).

Se ha dicho con acierto que la documentación inquisitorial constituye una fuente privilegiada para poder reconstruir estos aspectos de las tradiciones judías medievales, pues en las causas seguidas por el tribunal del Santo Oficio se describen minuciosamente los ritos que eran seguidos en riguroso secreto por los ya convertidos (Casanovas, 2003, p. 497; Cantera, 2015, p. 106). Sin embargo, también los procesos judiciales, aunque circunstancialmente y tal vez con menos detalles, proporcionan información sobre esas instancias. Tomaremos un ejemplo. Se trata de una causa judicial por cobro de una deuda, ${ }^{22}$ donde el acreedor (cristiano) pretendía que los herederos de un matrimonio judío asumieran el mencionado compromiso. Con pocos días de diferencia, el hombre y la mujer habían fallecido, víctimas de la misma enfermedad. Los interrogatorios presentados por las partes enfrentadas, para que con ellos se tomara declaración a los testigos, no tenían el propósito de transmitir para investigadores de siglos posteriores las costumbres seguidas en esos momentos, sino de dejar constancia quiénes se encontraban cuando Saúl y Úrsula (los esposos) murieron, explicar por qué motivo estaban allí, describir qué bienes había, etc. Gracias a estos testimonios sabemos que acudieron la madre de ella, los hermanos de ambos, sobrinos mayores, vecinos, y que los hijos (menores de edad) habían sido llevados a la casa de un tío, hermano de Úrsula. El rabí declaró que se hallaba en la cabecera de Saúl y "que oyó [su voluntad] estando para salírsele el alma", mientras que otros testigos describieron a doña Ester, madre de Úrsula, al lado del lecho de su hija. El "juez de la aljama" (también rabí) explicó que, al regresar del cementerio, muchos que acompañaban el cortejo fúnebre se separaron en la "puerta del barrio"-se refiere a la judería de Coruña del Conde, en el Obispado de Osma- para dirigirse a Peñaranda y otros pueblos aledaños, es decir que judíos de localidades próximas habían participado también de la ceremonia, lo que demuestra una vez más los vínculos extendidos entre los vecinos de distintas aljamas. ${ }^{23}$

22 ARCHV. Pleitos Civiles, Fernando Alonso (F), 1486-1496. Caja 1135-1.

23 En este caso, los vínculos se conformaban no solo a partir de lazos familiares (hermanos, primos, sobrinos... que habitaban en distintas localidades), sino también de actividades productivas (viñedos, molinos), comerciales, crediticias y de arrendamiento de rentas (reales y eclesiásticas). Cabe destacar que la mayoría de estas operaciones se realizaban en asociación con vecinos cristianos. He analizado esta cuestión en Caselli (2017b). 
Ya en el cementerio, el cuerpo era depositado en una fosa individual y, según la tradición sefardí, directamente en la tierra. De todas maneras, si bien el uso de ataúd era más común en las comunidades medievales askenazíes, su utilización no debe descartarse en el mundo hispanojudío. Durante la inhumación se pronunciaban rezos por el eterno descanso del difunto y se lo cubría con tierra, de modo provisional hasta tanto se colocara la lápida definitiva (Cantera, 2015, pp. 115-118).

Según la tradición, los cementerios judíos se ubicaban extramuros de las ciudades, como decíamos y, por lo general, para su protección se los rodeaba de un muro o de una hilera de árboles, asimismo, cuando existía la posibilidad, se los emplazaba en lugares elevados, procurando siempre que se tratara de tierra virgen (Cantera, 1998, pp. 168-169; Casanovas, 2003, p. 505). Las sepulturas diferían de un cementerio a otro: algunos se caracterizaban por fosas antropomorfas, otros, por fosas enmarcadas en piedras (Imagen 1) o con cámara lateral y, en ciertas zonas, prevalecía la construcción de lucillos. ${ }^{24}$ Las tumbas solían cubrirse con una lápida, tarea que habitualmente y de acuerdo a la tradición (Grinvald, 2006, p. 555) asumían los albaceas del difunto, siguiendo la testamentaría. En las necrópolis askenazíes, las lápidas eran pequeñas (50 centímetros por 30, aproximadamente) y se colocaban de manera vertical, mientras que en las sefardíes predominaban las grandes losas, de más de dos metros de longitud (Imagen 2), cubriendo con ellas toda la tumba (Cantera, 1998, p. 169).

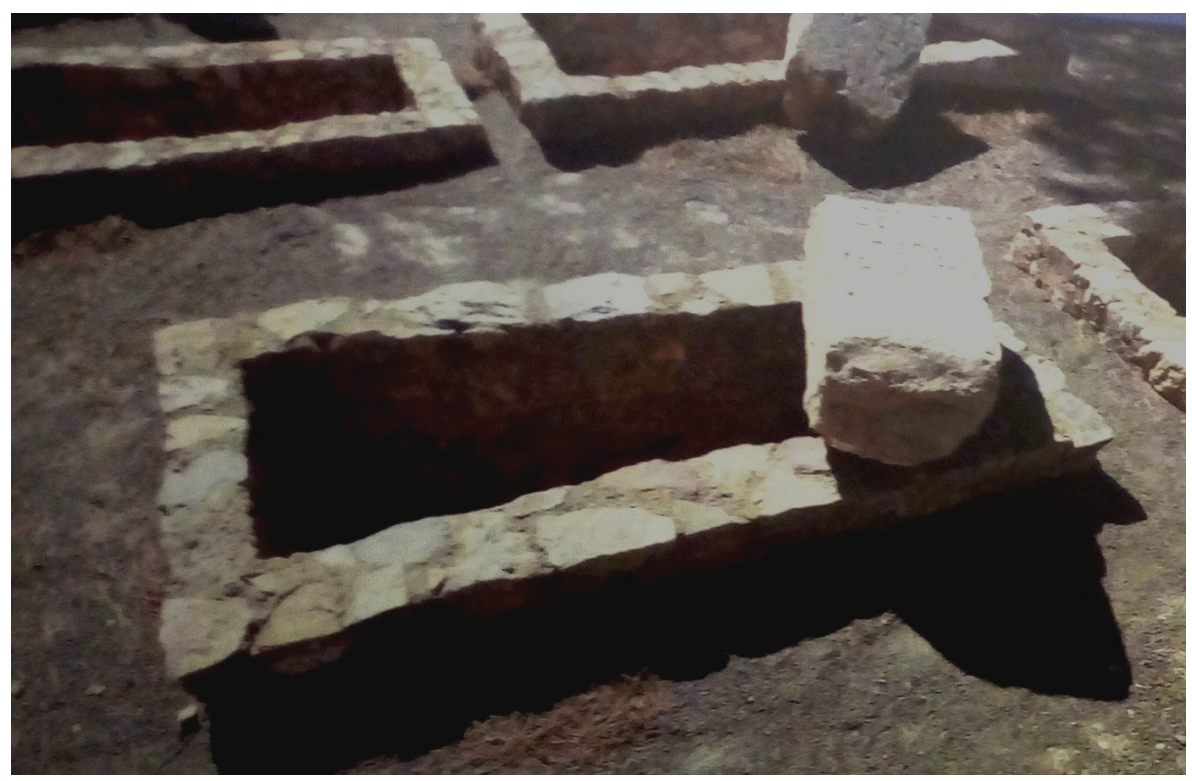

Imagen 1. Imagen de los hallazgos arqueológicos del cementerio judío de Sagunto (siglos XIII-XV), exhibida en el Museo Sefardí de Toledo. Fotografía de la autora.

24 Escapa a los propósitos de este trabajo describir minuciosamente los diversos tipos de enterramientos. Para una mayor información, puede consultarse, por ejemplo, Ruiz Taboada (2009 y 2014). Véase una descripción detallada en Casanovas (2003). 


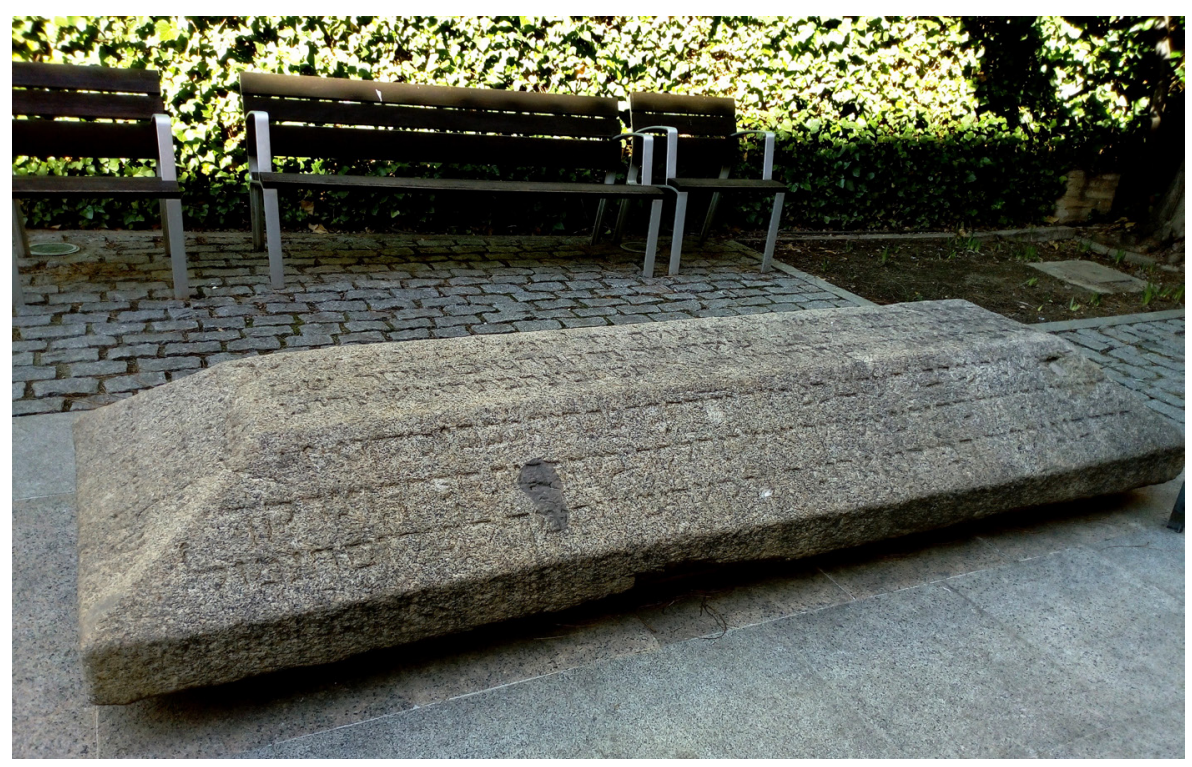

Imagen 2. Lápida exhibida en el Museo Sefardí de Toledo. Dimensiones: 2,73 m. x 0,92 m. x 0,34 m. Fotografía de la autora.

En los últimos años, las aportaciones de la arqueología han ampliado el conocimiento sobre los cementerios judíos y han ilustrado, asimismo, la variedad de las costumbres locales. ${ }^{25}$ En la Península Ibérica, se tienen referencias de 104 necrópolis hebreas, sobre un total de 98 localidades. No obstante, las fuentes arqueológicas brindan información solo sobre 22 de ellas. De estas, únicamente en 10 se han obtenido restos materiales que permiten constatar que se trata de cementerios judíos (Casanovas, 2003, p. 498). Los investigadores coinciden en señalar que tal limitación obedece-además de las dificultades propias de realizar excavaciones ${ }^{26}$ - esencialmente a la escasez de depósitos funerarios. Recordemos que, de acuerdo a la cultura judía, ningún ajuar acompañaba el enterramiento, los cuales, si hubieran existido, habrían permitido precisar con mayor claridad la identidad judía de las sepulturas. ${ }^{27}$ De todas maneras, se han hallado adornos o elementos -que no son ajuar propiamente dicho, sino aderezo personal- que facilitan la identificación. Tal dificultad es subsidiaria del principal problema que enfrentan los responsables de las excavaciones, que es la carencia casi total de piedras funerarias ${ }^{28}$ o elementos con escritura hebrea. ${ }^{29}$ Esta ausencia de la que se lamentan los arqueólogos no hace sino corroborar lo que se había constatado merced a otras fuentes documentales, esto es: la eliminación de todo rastro del judaísmo. Una vez concretada la salida de los judíos, cualquier vestigio material de la religión mosaica fue borrado o directamente destruido.

25 Existe una muy abundante bibliografía sobre las necrópolis judías y los avances en arqueología. A título orientativo pueden consultarse, por ejemplo: Casanovas (2003), Castaño (2007), Ruiz Taboada (2009, 2014 y 2016), Moreda y Serrano (2014), Colet y Saula (2014).

26 La mayoría de las veces los descubrimientos han sido más fruto de la casualidad que de una búsqueda planificada (Castaño, 2007, p. 221); en ocasiones, la remodelación de un espacio urbano o la construcción de nuevos edificios sacan a relucir, sin proponérselo, los restos de nuestros antepasados (Ruiz Taboada, 2014, p. 211). Y no siempre es fácil continuar la investigación con la minuciosidad que la tarea requiere. No obstante, se ha conseguido trabajar en yacimientos importantes como, por ejemplo, en Valladolid (Moreda y Serrano, 2014), en Tarrega (Colet y Saula, 2014) o en la zona toledana (Ruiz Taboada, 2009, 2014 y 2016).

27 Coinciden en tales afirmaciones: Moreda y Serrano (2014, p. 355), Colet y Saula (2014, p. 366), Ruiz Taboada (2014, p. 238) y Casanovas (2003, p. 522).

28 Así lo expresan Moreda y Serrano (2014, p. 361), Colet y Saula (2014, p. 366) y Ruiz Taboada (2014, p. 238).

29 Como ha señalado Javier Castaño (2007), desde el formidable trabajo de Francisco Cantera y José M. Millás a mediados del siglo XX - Las inscripciones hebraicas de España (1956)- en el que daban cuenta de la existencia de las inscripciones funerarias halladas, que en ese entonces no llegaban a treinta, paulatinamente se ha ido avanzando en el conocimiento y recuperación de los restos materiales de los judíos. Sin embargo, subsisten dificultades metodológicas y de interpretación, a la hora de identificarlos y clasificarlos. Sobre estas cuestiones ver el libro completo editado por Javier Castaño (2014). 


\section{El desmantelamiento de los cementerios}

Los cementerios, así como el resto de bienes comunales, quedaron a disposición de la Corona, que los cedió a través de distintas mercedes. La documentación revisada indica que, en su gran mayoría, se otorgaron de manera separada las lápidas y el solar correspondiente a los enterramientos. Los beneficiarios de tales mercedes fueron, por lo general, iglesias, conventos, monasterios y los concejos de las ciudades. A título ilustrativo, a continuación se detallan algunos casos que permiten apreciar las distintas formas que adquirieron las mencionadas donaciones reales, realizadas en su mayor parte entre finales de 1492 y mediados de 1493, cuya formalidad se expresaba en los siguientes términos:

por cuanto por la salida de los judíos de estos reinos e señoríos están a nuestra disposición los onsarios y enterramientos que los dichos judíos tenían, por ende, nos como de cosa nuestra propia acatando la devoción que habemos e tenemos al monasterio de San Vicente de la ciudad de Plasencia (...) les hacemos merced, gracia e limosna de la piedra e ladrillo que en el onsario e enterramiento (...) estuviere para obra de la iglesia de dicho monasterio que ahora se hace... ${ }^{30}$

El ejemplo resulta especialmente interesante pues, si bien su texto no difiere de los habituales otorgamientos por merced real, deja en evidencia las complejidades tejidas en torno a los bienes pertenecientes a judíos. En este caso, la aljama intentó, a través de un apoderado, vender sus bienes comunales -entre otros, el cementerio-. Por escritura notarial del 21 de mayo de 1492, Yuçé Castaño, en representación de la aljama de Plasencia, vendía al reverendo don Diego de Jerez, deán de la iglesia catedral de dicha ciudad, "los honsarios de los judíos de la dicha aljama (...) que tenemos (...) en el Berrocal desta dicha ciudad, con toda la piedra e cantería que en ellos está", ${ }^{1}$ por la exigua suma de 400 reales de plata. Esta cifra, realmente insignificante, fue objetada por varios judíos, dejando en clara evidencia el desacuerdo, un hecho que de ningún modo debe llamar la atención, pues las disputas y enfrentamientos, a veces violentos, eran bastante habituales en el interior de las aljamas (Caselli, 2016, pp. 184-198). Ante tales reparos, el comprador exigió una ratificación expresa de aceptación de la venta por parte del conjunto de la aljama, que esta suscribió pero dejando de manifiesto que el valor real del inmueble era muy superior. En el documento notarial se lee:

E por cuanto la dicha aljama e yo conocemos verdaderamente que los dichos sitios e piedra e cantería labrada e por labrar dellos, valen más cuantía de los dichos cuatrocientos reales (...) por esta presente carta, vos hacemos gracia y pura donación no revocable (...) por muchas y buenas obras que la dicha aljama ha recibido de vos el dicho señor deán. ${ }^{32}$

En otras palabras, el comprador, a sabiendas de que adquiría el inmueble con todo lo en él implantado y contenido, por una cifra irrisoria, hizo constar en la escritura que la diferencia entre el valor real y el precio pagado constituía una donación que voluntariamente los miembros de la comunidad judía le hacían. Ahora bien, como puede verse en el documento citado más arriba, en el mes de noviembre de ese mismo año, los Reyes Católicos hicieron merced al monasterio de San Vicente, de la "piedra e ladrillo" de dicho cementerio, que sin embargo, ya había sido comprado por el deán de la Catedral-lo cual generaría reclamos y discusiones entre ambas instituciones religiosas- quien, por su parte, unos años más tarde vendería dicho predio a la ciudad (De Hervás, 1999a, p. 74).

30 AGS. RGS. 1492.11.15. Se aclara que todas las reproducciones de documentos, aunque trasladadas al castellano actual, son rigurosamente literales.

31 ACP, 6, 30, reproducido en De Hervás (1999b).

32 ACP, 6, 30, reproducido en De Hervás (1999b). 
Asimismo, resulta importante destacar que estas mercedes no eran espontáneas sino que respondían a peticiones elevadas por los interesados; solicitudes que con frecuencia coincidían con las presentadas por otros pretendientes. Vale decir que los cementerios también fueron objeto de litigios entre cristianos. La mayoría de las veces, dichos pedidos se hacían llegar cuando ya se había concretado la apropiación de los bienes en cuestión. Así sucedió en Miranda de Ebro, donde la aljama también había intentado vender los bienes comunales, pero el concejo de Burgos, bajo cuya jurisdicción se hallaba la villa, vetó la iniciativa. La medida fue posteriormente rectificada tras una apelación presentada por los judíos (Cantera, 2005, p. 74). Sin embargo, para ese entonces, la sinagoga ya había sido tomada por el concejo de Miranda de Ebro para "casa del ayuntamiento" y las piedras del osario para su arreglo y reacondicionamiento. Luego, con los hechos consumados, suplicaron a los reyes que se les hiciera merced. ${ }^{33}$ Algo similar ocurrió en Huesca. En este caso, en el mes de junio de 1492, es decir, sin siquiera aguardar a que se cumpliera el plazo establecido para la salida de los judíos, los inquisidores presentes en la ciudad confiscaron el fosal. Los custodios de la fe vieron ante sí una excelente oportunidad para aprovechar las lápidas, que destinaron a la reparación de la muralla. Acto seguido, comisionaron a un representante para que solicitara ante la Corte que Sus Altezas hicieran "mercet dellas a la ciudat". ${ }^{34}$ Una vez más la apropiación había precedido a la merced real.

El caso del cementerio de Vitoria constituye otro ejemplo de la complejidad a la que aludíamos. Un mes antes de la fecha estipulada para la salida, la aljama llegó a un acuerdo con el concejo de dicha ciudad, mediante el cual le cedían a esta institución el cementerio a cambio del compromiso, por parte de las autoridades cristianas, de que el predio no sería utilizado para labores agrícolas ni se construiría sobre él. Enrique Cantera (2005, p. 77) aporta un documento concejil donde consta que, al menos hasta finales de 1492, el ayuntamiento procuró respetar dicho acuerdo. Con anterioridad, Luis Suárez Fernández (1964, p. 51), basándose en Amador de los Ríos, había afirmado que "la ciudad ha cumplido cuidadosamente este viejo legado". Sin embargo, como hemos podido constatar, unos meses más tarde (junio de 1493) y tras una solicitud presentada ante el Consejo Real por la iglesia Santa María Mayor de Vitoria, la sinagoga, más un solar anexo y las piedras del osario (pedidas para refacción de la iglesia), fueron concedidas como merced real a esta institución religiosa. ${ }^{35}$ Por lo tanto, y al igual que el resto de las necrópolis judías, las sepulturas de este cementerio fueron también ultrajadas.

Por su parte, las autoridades del monasterio de Santa María del Parral, de Segovia, en una presentación efectuada en 1493, explicaban el menoscabo que la expulsión de los judíos había significado para dicho monasterio, pues este tenía un situado de 5.000 maravedíes anuales sobre las alcabalas de las carnicerías judías de la ciudad, renta que evidentemente la institución había perdido. En consecuencia, les solicitaban a los reyes que les concedieran otro situado sobre alcabalas, pero "que sean ciertos". En su respuesta, los monarcas les recordaron el propósito supremo que había motivado la expulsión y que, por lo tanto, ningún reclamo se justificaba: "acatadas las causas justas porque mandamos salir a los judíos no éramos obligados a sanear (...) dicho juro ni dar equivalencia de ellos". No obstante, les hicieron merced de la nada desdeñable suma de 100.000 maravedíes sobre los bienes comunales dejados por los judíos, comenzando por la sinagoga mayor. En el mismo documento se disponía que si la valuación del edificio no alcanzaba tal cifra, el monto se completara con las lápidas del enterramiento de los judíos, siempre que el "suelo quede por ejido común de

33 AGS. RGS. 1493.06 .32 .

34 Documento citado en Motis Dolader (1998, pp. 195-196).

35 AGS. RGS. 1493.06.33. 
la dicha ciudad". ${ }^{36}$ Huelga decir que allí también el cementerio fue inmediatamente desmantelado. El hecho de dejar el solar para aprovechamiento de la ciudad respondía a reclamos constantes de los concejos, que veían en tales donaciones un perjuicio notorio: si el espacio del cementerio pasaba a manos privadas, ello implicaría un detrimento evidente del término comunal. Idéntica preocupación manifestaban "los hombres buenos de la ciudad de Calahorra", al tomar noticia de que varios vecinos de la localidad habían recibido, por merced real, las lápidas del cementerio judío. Según expresaban, ellos temían que los beneficiarios se quisieran "aprovechar no solamente de la piedra del dicho onsario mas aun del suelo de él". Suplicaban, por ende, que se especificara que el solar permanecería en manos del concejo, para que allí pacieran "sus ganados". 37

Un ejemplo más. El cementerio de Ávila fue cedido por merced al Monasterio de Santo Tomás de dicha ciudad. ${ }^{38}$ En abril de 1494 , se realizó el acto formal de traspaso: en presencia del escribano Pedro Domínguez, se presentó Juan Verdugo como procurador del monasterio de Santo Tomás y, exhibiendo la carta real de merced, procedió a tomar posesión de los bienes:

[...] el dicho Juan Verdugo dijo que en el dicho nombre toma e tomó, aprehendía e aprehendió la posesión real corporal habitual del dicho fonsario y tierra y sitio y piedra (...). E en señal de posesión que así toma y tomó, hizo ciertas cruces en ciertas piedras del dicho onsario con una pica de hierro y cavó con un azadón en la dicha tierra del dicho onsario (...). E pidiolo por testimonio... ${ }^{39}$

La cita adquiere para nosotros una doble relevancia. Por un lado, resulta elocuente respecto de la violación flagrante del cementerio: se describe con claridad cómo excavaban la tierra y cincelaban las lápidas en señal de posesión. Por otro, es ilustrativa de escenas que, aunque con variantes, se han reiterado en cada ciudad, en cada villa. De allí que en estas páginas se insista en remarcar que se trató de una profanación total y absoluta.

\section{Los judeoconversos ante la destrucción de los cementerios}

En las páginas precedentes, hemos ofrecido una descripción concreta, aunque sucinta, de ciertos aspectos culturales y materiales de los cementerios judíos medievales. Asimismo, hemos sintetizado el destino que, junto a otros bienes comunales sefarditas, sufrieron los enterramientos y osarios, sin descuidar las circunstancias económicas y políticas que intervinieron en ese proceso, que no fue sino de destrucción y eliminación sistemática de todo rastro de la religión y cultura judías de los reinos hispánicos. Toca ahora abordar la preocupación central que guía el presente trabajo, esto es, interrogarnos sobre cómo habrá afectado a los hombres y mujeres en ese momento recién convertidos la desaparición material de los lugares sagrados de su anterior religión. Los motivos de las conversiones pueden ser insondables pero lo más plausible es que en aquel contexto quienes asumieron la decisión de abandonar (formalmente) el judaísmo lo hicieran para salvarse de la expulsión y poder permanecer en su lugar, en definitiva, para poder continuar con sus vidas. Es más que probable, entonces, que siguieran apegados a su fe; más aún aquellos que habían sido

\footnotetext{
36 AGS. RGS. 1493.01.17.

37 AGS. RGS. 1492.08.159.

38 AGS. RGS. 1494.03.1.

39 Archivo Municipal de Ávila. Documento 1/92, reproducido por León Tello (1963, pp. 101-103). El resaltado me pertenece.
} 
capaces de abandonarlo todo y, con tal de no renunciar a ella, partieron al exilio y, como consecuencia de las adversidades del destierro, decidieron regresar resignados a aceptar el bautismo. En tales circunstancias, es central cuestionarse qué significancia pudo tener para ellos la desaparición de las sinagogas y, lo que más interesa aquí, el desmantelamiento de los cementerios, con el subsiguiente levantamiento y traslado de las lápidas que guardaban las sepulturas de sus seres queridos. En otras palabras, se trata de poner en consideración el hecho de que fueran testigos de dichas profanaciones. Tras estos interrogantes surgen otros, si se quiere subsidiarios de los primeros: si esa experiencia pudo incidir en sus conductas o sus actitudes en tanto cristianos, si generó resentimiento hacia los autores directos, si alimentó su apego al judaísmo y, por ende, su reticencia hacia a la nueva religión. Por supuesto que no resulta sencillo ofrecer respuestas taxativas a interrogantes que refieren a motivaciones tan profundas, tan difíciles de asir. No obstante, estas dificultades de ningún modo deben erigirse como un obstáculo que impida inquirir sobre tales aspectos, aunque rara vez estos se encuentren claramente expuestos en la documentación estudiada. Por el contrario, creemos que es preciso indagar sobre (y tratar de ponderar) el papel que pudieron jugar dichas experiencias en el proceso de integración de los judeoconversos españoles. Nuestro propósito fundamental es dejar, cuanto menos, planteados estos interrogantes.

Un punto de partida clave para inferir las aflicciones que pudieron nacer en quienes fueron testigos de la destrucción de los cementerios es entender qué significado tenían para ellos los sitios de enterramiento. Comencemos por recordar que para la religión judía el cementerio representa un espacio sagrado, estimado como "tierra santa", no se trata solo de un sitio de dolor o de culto, "ma è sopra tutto un luogo dove ci si reca per onorare i propri cari, per pensare alla propia vita trascorsa e a quella che rimarrà da vivere” (Brunetti y Della Rocca, 2007, p. 240). Así, preservar las sepulturas y su entorno es considerado un verdadero acto de piedad, porque a través de él se cuida y se respeta la memoria de los muertos. Por ello, corresponde mantener allí un comportamiento apropiado. No se debe comer, beber, ni realizar ninguna otra actividad que pueda resultar inadecuada u ofensiva. Para el período estudiado, las Responsa rabínicas ayudan a un mejor conocimiento respecto de la sacralidad de los enterramientos. En ellas abundan cuestiones relativas a, por ejemplo, la prohibición de sentarse sobre las lápidas o de cambiar una lápida por otra más nueva.$^{40} \mathrm{Del} \mathrm{mismo}$ modo, el compendio de Leyes elaborado por Iosef Karo ${ }^{41}$ recordaba la importancia de las visitas que debían realizarse al cementerio, así como el ritual a seguir, muy especialmente, al cumplirse el primer aniversario de la muerte de cualquier ser querido y, en particular, de los padres (Karo, 1956, pp. 284-286).

De la trascendencia que para la cultura sefardí tenían los cementerios dan cuenta, asimismo, las donaciones que algunas aljamas efectuaron antes del destierro, como parte de un convenio realizado con el fin de que el sitio sagrado no fuera ultrajado, aunque luego dicho acuerdo no se respetara. En otros casos, en cambio, previendo que de todos modos sinagogas y cementerios serían desmantelados, procuraron vender los bienes de la aljama, como sucedió en Plasencia. Claro que, tanto en las gestiones comunales como en las particulares, lo que primó fue el abuso. ${ }^{42} \mathrm{El}$ temor -o, mejor

40 Salomón ben Adret, Responsa, Libro I, pp. 296 y 537, citado en Casanovas (2003: p. 495).

41 Según nos recuerda Natan Lerner en el "Prólogo" al Shuljan Aruj, losef Karo había nacido en Toledo en 1488. Al dictarse el decreto de expulsión, emigró junto a su familia, primero a Portugal y luego hacia el Mediterráneo oriental. Tras diversas migraciones, se radicó en Safed, donde falleció en 1575. En esta última ciudad, se ordenó como rabino, ejerció la docencia y fue asimismo allí donde escribió estas reglas para que, de acuerdo a sus propósitos, sirvieran de guía y fácil consulta. Es considerado uno de los grandes jurisconsultos judíos (Karo, 1956, pp. 11-13).

42 En este punto, resulta importante señalar que numerosas familias de Plasencia, que inicialmente se habían exiliado (por lo general, en Portugal), luego retornaron bautizadas y reclamaron ante la justicia por recomprar sus bienes al mismo valor en que los habían vendido. En tales demandas se comprueba, una vez más, el aprovechamiento del que habían sido víctimas por parte de los compradores. 
dicho, la certeza- de que sobrevendría una destrucción inminente de los cementerios no nacía de ninguna intuición o perspicacia sino de la experiencia. Durante mucho tiempo, los judíos se habían visto obligados a defender los lugares de enterramientos de las agresiones que, con suma frecuencia, perpetraban los cristianos, quienes solían arrojar allí basura, estiércol, cavaban hoyos, llevaban a pacer sus animales, etc. (Casanovas, 2003, pp. 523-525).

Por otra parte, y como ha advertido ya hace tiempo Philippe Ariès (2017, p. 13), los testamentos constituyen una fuente esencial para abordar las actitudes ante la muerte en distintas épocas. En nuestro caso, pueden ayudarnos a reconstruir la importancia que judías y judíos le otorgaban al lugar para el descanso eterno. En estos documentos es habitual hallar deseos como los manifestados por don Judá, vecino de Alba de Tormes: "Que mi cuerpo sea puesto en mortaja y que me entierren en el campo dorado, do yacen nuestros padres y pasados". A menudo aparece el deseo de ser depositado en proximidad de donde se encontraban enterrados familiares cercanos. Así, la voluntad de doña Jamila, vecina de Zaragoza, era que su cuerpo fuera enterrado "cerca de do yace el de mi marido, Don Gento"; o bien, como expresaba don Zunana, residente de Épila: "cerca e a costado de donde yace mi madre, la cual sepultura quiero que me sea hecha bien e honradamente (...) e que me sea puesta una piedra de precio de treinta sueldos". Asimismo, se solía encomendar ser inhumado en un sitio próximo a donde descansaban amigos o personajes conocidos y respetados: don Samuel Franco, también de Zaragoza, pedía que lo enterrasen "cerca de la sepultura de Don Salomón Constantin" o "cerca de la sepultura de los Abnarrabis". ${ }^{43}$ Respetar estas voluntades, junto con la ceremonia de las exequias, el duelo posterior y la colocación de una lápida, por lo general al cumplirse el primer aniversario, a la vez que constituían un deber religioso más, eran considerados actos piadosos que ayudaban al alma del muerto en su tránsito celestial (Grinvald, 2006, pp. 535-557).

Las crónicas que algunos judíos escribieron en el exilio ofrecen un relato desgarrador de los padecimientos sufridos en el destierro (Bar Selomoh, 1992; Ha-Kohen, 1989). Estos sufrimientos, en muchos casos, provocaron que quienes lo habían sacrificado todo por mantener su fe -malvendiendo sus bienes y dejando atrás el que había sido, por generaciones, el lugar de su familia- tomaran la decisión de regresar. Las fuentes estudiadas permiten corroborar algunos pasajes de estas crónicas, a veces consideradas lacrimógenas o extremas. ${ }^{44}$ Los procesos judiciales nos han permitido reconstruir, por ejemplo, las vejaciones sufridas en alta mar por parte de capitanes que debían trasladarlos al norte de África; 45 el episodio de los niños entregados como esclavos por el rey de Portugal a un capitán con el fin de poblar unas islas; ${ }^{46} \mathrm{o}$, más extensamente, las enfermedades y muertes padecidas en el exilio, donde algunas familias quedaron realmente diezmadas. ${ }^{47}$ No se trata de mostrar un relato lacrimógeno sino de dar cuenta de una historia trágica.

Estas crónicas, elaboradas desde el exilio, relatan la pesadumbre y desolación del destierro, pero nada dicen, por razones obvias, de las angustias vividas, ya en los

43 Las citas de testamentos son reproducidas en Casanovas (2003, pp. 496-497).

44 Una explicación sobre esta postura en Nirenberg (2001, p. 9).

45 Por ejemplo, en AGS. RGS. 1494.07.227 constan las denuncias presentadas por judíos que regresaron convertidos contra el Capitán Andino, vasallo del duque de Medina Sidonia, donde lo acusan de haber cometido contra ellos y sus familias "mil ultrajes e injurias".

46 Este episodio que las crónicas recuerdan como una gran tragedia -tal es el caso de Consolação às Tribulações de Israel, en el capítulo que reza: "Portugal, ano 5253, quando mandaron os mininos aos lagartos" (Martins, 2006, pp. 134-135)- lo encontramos relatado en la voz de un testigo en el proceso judicial: AGS. Consejo Real de Castilla 1515/16-23-7.

47 Por ejemplo, de una de las familias emigradas de la Villa de Pedraza, solo dos de sus siete miembros sobrevivieron al destierro. Hemos podido reconstruir el caso a través del siguiente proceso judicial: ARCHV. PI. Civiles F. Alonso (F) $1512 / 1513-596-1$. 
reinos hispánicos, por aquellos que decidieron regresar. Por lo tanto, no transmiten la desazón que ante la destrucción de sinagogas y cementerios pudieron experimentar los conversos que retornaron ni tampoco la de aquellos que se habían convertido cuando la orden de destierro. Sin embargo, una de ellas cuenta que, mucho antes de que se conociera el edicto de expulsión, a Rabí Isaq León se le presentó su difunta mujer en sueños y, como si fuera un presagio, le advirtió: "quita la lápida de mi sepulcro y haz que labren sobre él y que no se sepa más el lugar de mi reposo" (Ha-Kohen, 1989, p. 118). El sueño, que sería interpretado luego como un vaticinio funesto, no había sido sobre la casa, ni sobre la sinagoga que deberían abandonar, sino sobre la tumba de su esposa.

\section{Reflexiones finales}

Como es sabido, se ha debatido largamente respecto de la situación de los conversos con relación a la comunidad cristianovieja. La extensión del debate impide que demos aquí una cuenta acabada de él, solo nos limitaremos a apuntar que las controversias giraron principalmente en torno de la sinceridad de las conversiones. Al respecto, Caro Baroja propuso hace ya varias décadas una gradación, ${ }^{48}$ la cual ha sido retomada y ampliada por diversos estudiosos ${ }^{49}$ al margen de aquellos que se sitúan en las posturas extremas de integración completa o bien de rechazo absoluto. ${ }^{50}$ Un punto clave a considerar es en qué momento histórico se centra el análisis; en este sentido, la generación que atravesó la coyuntura de la expulsión, enfrentándose a la obligación de optar entre exilio o bautismo, merece una atención singular. Las discusiones sobre los niveles de judaización o práctica secreta de la religión judía contemplan temas esenciales como son, por un lado, las posibilidades limitadas de continuar formándose en la Ley de Moisés -en especial con posterioridad a 1492- y, por otro, la falta de una adecuada instrucción cristiana. ${ }^{51}$ Sin embargo, no se han atendido ni observado otros acontecimientos que fueron vividos únicamente por aquella generación y que, a nuestro juicio, resultan fundamentales a la hora de reflexionar sobre las circunstancias probables que condujeron a muchos conversos de ese tiempo a persistir en su fe anterior, resistir de manera soterrada su integración a la comunidad cristiana o, en todo caso, transitar una asimilación cargada de complejidades.

Además de haber presenciado la transformación de sinagogas en iglesias, en hospitales o en otras instituciones, hecho de por sí doloroso para cualquier judío, nos ha interesado hacer aquí particular hincapié en la destrucción de los cementerios. La documentación hasta ahora hallada da cuenta del desmantelamiento de los enterramientos de dieciséis localidades: Ávila, Badajoz, Burgos, Calahorra, Ciudad Rodrigo, Guadalajara, Miranda del Ebro, Murcia, Palencia, Pastrana, Plasencia, Segovia, Toledo, Trujillo, Turégano y Vitoria. Entendemos que constituyen testimonios significativos, tanto por su número -no debe olvidarse que son documentos originados en pleitos judiciales circunscritos al ámbito jurisdiccional estudiado; allí donde no hubo litigios, no encontramos sus trazos en los repositorios consultados- como por su cobertura geográfica, lo cual, sumado a las constataciones arqueológicas, permitiría pensar que se trató de un fenómeno que abarcó el conjunto de las ciudades hispánicas donde existió una comunidad judía.

48 Según Caro Baroja, los diversos tipos serían: conversos buenos católicos, heterodoxos dentro del cristianismo, conversos talmudistas, conversos heterodoxos dentro del judaísmo, conversos incrédulos y conversos vacilantes. Este último sería uno de los más nutridos, en palabras del autor (2000, p. 293 y ss).

49 Es el caso del completo trabajo de David Gitlitz (2003, pp. 95-106).

50 Ejemplificado más arriba en las posturas opuestas entre Haim Beinart (1992) y Benzion Netanyahu (2002).

51 El tema es referido en Bel Bravo (2006, p. 228). Ver asimismo el estudio minucioso de Rábade Obradó (1999, passim). 
Nos hemos preguntado respecto del impacto que la profanación y posterior destrucción de tumbas de familiares y amigos hubieron de provocar en aquellos hombres y mujeres recién convertidos. Si bien no hemos hallado testimonios palmarios de esos sentimientos, fuentes indirectas nos informan de la importancia que para ellos tenían los cementerios, no solo como lugar de reposo eterno sino también como espacio sagrado, de rezo y recogimiento en memoria de las almas de los muertos. Del mismo modo, lo deja ver la preocupación que por su cuidado había sido puesta de manifiesto por los judíos, en momentos anteriores, ante los avasallamientos operados por cristianos. De la trascendencia del sitio para el descanso eterno dan cuenta también los testamentos, que otorgan a esa cuestión un espacio inicial y principal. Todos estos trazos permiten sin dudas inferir lo que habrá significado su devastación.

A la tragedia de la expulsión, relatada en las crónicas y constatada en la documentación estudiada, para los convertidos en esas circunstancias, vino a sumarse la obligación de olvidar su anterior religión, de callar ante el desmantelamiento de las sinagogas y, en especial, ante la profanación total y absoluta de los cementerios. Entendemos que la convivencia con quienes se habían servido de las lápidas para construir un muro o un camino, o con aquellos que pacían sus ganados en los solares donde se hallaban sepultados sus seres queridos, no habrá sido fácil de sobrellevar. Y, aun desconociendo cuánto tiempo habrán conservado aquellas imágenes o si las han transmitido a sus descendientes, bien podemos suponer que esos sentimientos se encontraban lejos de propender a una aceptación no conflictiva de la nueva religión y a una inserción sin contradicciones en la comunidad cristianovieja. Nuestra propuesta, por lo tanto, es insistir en que la desaparición material de sinagogas y, en especial, la destrucción de cementerios deben erigirse como un tema insoslayable cada vez que se pretenda analizar y problematizar el grado de asimilación, el tránsito hacia la integración o la sinceridad de las conversiones de aquella generación protagonista involuntaria de la orden de destierro de 1492. 


\section{Bibliografía}

" Alcalá, Á. (Ed.). (1995). Judíos. Sefarditas. Conversos. La expulsión de 1492 y sus consecuencias. Valladolid: Ámbito.

" Ariès, P. (2017 [1975]). Historia de la muerte en Occidente. Desde la Edad Media hasta nuestros días. Barcelona: El Acantilado.

" Baer, Y. (1998). Historia de los judíos en la España cristiana. Barcelona: Riopiedras.

» Bar Selomoh, A. (1992). Sefer ha-qabbalah. En Dos crónicas hispanohebreas del siglo XV (67-112) (Trad. y notas Moreno Koch, Y.). Barcelona: Riopiedras.

"Beinart, H. (1983). Los conversos ante el Tribunal de la Inquisición. Barcelona: Riopiedras.

» Beinart, H. (1992). Entrevista a Haim Beinart. En Diario ABC. Edición 31/03/1992.

» Beinart, H. (1995). Vuelta de judíos a España después de la expulsión. En Alcalá, A. (Ed.), Judíos, Sefarditas y Conversos. La expulsión de 1492 y sus consecuencias (181-194). Valladolid: Ámbito.

" Beinart, H. (2002). The Expulsion of the Jews from Spain. Oxford: The Littman Library of Jewish Civilization.

"Bel Bravo, M. (2006). Sefarad. Los judíos de España. Madrid: Sílex.

"Ben Saddiq, Y. (1992). Compendio Memoria del justo. En Dos crónicas hispanohebreas del siglo XV (21-65) (Trad. y notas Moreno Koch, Y.). Barcelona: Riopiedras.

" Benito Ruano, E. (2000 [1976]). Los orígenes del problema converso. Madrid: Real Academia de la Historia.

»Brunetti Luzzati, S. y Della Rocca, R. (2007). Ebraismo. Milán: Electa.

"Cantera Montenegro, E. (1979). Judíos de Torrelaguna: retorno de algunos expulsados. Sefarad, 39, 333-346.

»Cantera Montenegro, E. (1998). Aspectos de la vida cotidiana de los judíos en la España medieval. Madrid: Universidad Nacional de Educación a Distancia.

»Cantera Montenegro, E. (2005). Los últimos tiempos de la presencia judía en Calahorra y La Rioja, Kalakorikos, 10, 57-85.

"Cantera Montenegro, E. (2015). El día y las horas de los judíos españoles de la Edad Media. Madrid: CECEL-CSIC.

»Cantera, F. y Millás, J. (1956). Las inscripciones hebraicas de España. Madrid: CSIC. Instituto Arias Montano.

"Caro Baroja, J. (1986 [1961]). Los judíos en la España Moderna y Contemporánea., II-III. Madrid: Istmo.

»Caro Baroja, J. (2000 [1961]). Los judíos en la España Moderna y Contemporánea. Tomo I. Madrid: Istmo.

»Casanovas Miró, J. (2003). Las necrópolis judías hispanas. Las fuentes y la documentación frente a la realidad arqueológica. En López Álvarez, A. e Izquierdo Benito, R. (Eds.), Juderías y sinagogas de la Sefarad medieval. En memoria de José Luis Lacave Riaño (493531). Cuenca: Universidad Castilla-La Mancha.

"Caselli, E. (2008). La administración de justicia y la vida cotidiana. Judíos y cristianos en el ámbito jurisdiccional de la Corona de Castilla (siglo XV). Historia Social, 62, 3-25. 
»Caselli, E. (2011). Del exilio al terruño. Las reclamaciones ante la justicia de judíos que regresaron bautizados (Chancillería de Valladolid, 1492-1525). Chronica Nova, 37, 143-174.

»Caselli, E. (2016). Antijudaïsme, pouvoir politique et administration de la justice. Juifs, chrétiens et convertis dans l'espace juridictionnel de la Chancillería de Valladolid (XVe XVle siècles). Lille: ANRT.

»Caselli, E. (2017a). Antesala de la resignación. La frontera como espacio de espera para los judíos expulsados (Reinos de Castilla y Portugal, finales del siglo XV). En Favarò, V., Merluzzi, M. y Sabatini, G. (Eds.), Fronteras. Procesos y prácticas de integración y conflictos entre Europa y América (Siglos XVI- XX) (269-284). Madrid: Fondo de Cultura Económica.

"Caselli, E. (2017b). Judíos y eclesiásticos del Obispado de Osma: arrendamiento de rentas y circulación del crédito (Castilla, siglo XV). En Romani, M. (Ed.), Storia economica e storia degli ebrei. Istituzioni, capitale sociale e stereotipi (secc. XV-XVIII) (23-43). Milán: Franco Angeli.

»Castaño, J. (2007). Una menorá grabada hallada en Gredos. Sefarad, 67(1), 221-228.

»Castaño, J. (Ed.). (2014). ¿Una Sefarad inventada? Los problemas de interpretación de los restos materiales de los judíos en España. Córdoba: El Almendro.

» Colet i Marcé, A. y Saula i Briansó, O. (2014). El cementerio medieval judío de Les Roquetes (Tarrega d’Urgell). En Castaño, J. (Ed.), ¿Una Sefarad inventada? Los problemas de interpretación de los restos materiales de los judíos en España (363-370). Córdoba: El Almendro.

»Contreras, J. (1992). Sotos contra Riquelmes. Regidores, inquisidores y criptojudíos. Madrid: Anaya \& Mario Muchnik.

»De Hervás, M. (1999a). Documentos sobre los judíos de Plasencia en el Archivo Catedralicio (1411-1492), Parte I. Sefarad, 59(1), 53-76.

»De Hervás, M. (1999b). Documentos sobre los judíos de Plasencia en el Archivo Catedralicio (1411-1492), Parte II. Sefarad, 59(2), 263-307.

»Dedieu, J. P. (1992). ¿Pecado original o pecado social? Reflexiones en torno a la constitución y a la definición del grupo judeo-converso en Castilla, Manuscrits, 10, 61-76.

»Domínguez Ortiz, A. (1992). Los judeoconversos en la España Moderna. Madrid: Mapfre.

»Egido, T. (1997). La defensa de los conversos. En Martínez Ruíz, E. y Pazzis Pi, M. (Eds.), Instituciones de la España Moderna, 2. Dogmatismo e intolerancia (191-208). Madrid: Actas.

» García Cárcel, R. (1980). Herejía y sociedad en el siglo XVI. La inquisición en Valencia 15301609. Barcelona: Ediciones Península.

» Gitlitz, D. (2003). Secreto y engaño. La religión de los criptojudíos. Salamanca: Junta de Castilla y León.

» González Salinero, R. (2000). El antijudaísmo cristiano occidental (siglos IV y V). Madrid: Trotta.

» Grinvald, Z. (2006). Las Puertas de la Ley. Buenos Aires-Barcelona: Ediciones Obelisco.

» Ha-Kohen, Y. (1989). El valle del Ilanto. Crónica hebrea del siglo XVI. Barcelona: Riopiedras.

» Haliczer, S. (1997). La persecución de los judeoconversos en España y América. En Levaggi, A. (Coord.), La Inquisición en Hispanoamérica (43-64). Buenos Aires: Ediciones Ciudad Argentina.

» Huerga Criado, P. (2000). El problema de la comunidad judeoconversa. En Pérez Villanueva, J. y Escandell Bonet, B. (Dirs.), Historia de la Inquisición en España y América, t. III (441-498). Madrid: Centro de Estudios Inquisitoriales. 
» Kamen, H. (1985). La Inquisición española. Barcelona: Crítica.

» Kamen, H. (1988). The Mediterranean and the Expulsion of Spanish Jews in 1492. Past and Present, 119, 30-55.

» Kaplan, Y. (1996). Judíos nuevos en Amsterdam. Estudio sobre la historia social e intelectual del judaísmo sefardí en el siglo XVII. Barcelona: Gedisa.

» Karo, I. (1956 [1557]). Síntesis del Shuljan Aruj. Buenos Aires: Sigal.

» Kriegel, M. (2002). Le marranisme. Histoire intelligible et mémoire vivante. Annales, $57(2), 323-334$.

»Ladero Quesada, M. A. (1995). El número de judíos en la España de 1492: los que se fueron. En Alcalá, A. (Ed.), Judíos, Sefarditas y Conversos. La expulsión de 1492 y sus consecuencias (170-180). Valladolid: Ámbito.

» Lara Olmo, J. (1998). La polémica de Albaro de Córdoba con Bodón/Eleazar. En Del Valle Rodríguez, C. (Ed.), La controversia judeocristiana en España (Desde los orígenes hasta el siglo XIII) (131-16o). Madrid: CSIC.

» León Tello, P. (1963). Judíos de Ávila. Ávila: Diputación Provincial de Ávila.

»López Vela, R. (2008). La Inquisición en la ciudad: limpieza de sangre y conflictos con la Iglesia en Burgos. En Fortea, J. y Gelabert, J. (Eds.), Ciudades en conflicto (siglos XVI-XVIII) (259-278). Valladolid: Junta de Castilla y León - Marcial Pons.

» Marcu, V. (2012 [1934]). La expulsión de los judíos de España. Madrid: Renacimiento.

» Martins, J. (2006). Portugal e os judeos, Vol. I. Lisboa: Nova Vega.

» Momigliano, A. (1996 [1987]). De paganos, judíos y cristianos. México: Fondo de Cultura Económica.

» Moreda Blanco, F. y Serrano Noriega, R. (2014). El cementerio judío del Paseo de la Acera de Recoletos (Valladolid). En Castaño, J. (Ed.), ¿Una Sefarad inventada? Los problemas de interpretación de los restos materiales de los judíos en España (349-361). Córdoba: El Almendro.

» Motis Dolader, M. A. (1998). La aljama judía de Jaca en el siglo XV. Huesca: Ayuntamiento de Huesca.

»Netanyahu, B. (2002). Los marranos españoles según las fuentes hebreas de la época (siglos XIV-XVI). Valladolid: Junta de Castilla y León.

» Nirenberg, D. (2001). Violence et minorités au Moyen Âge. París: Presses Universitaires de France.

》 Pacios López, A. (1957). La Disputa de Tortosa, I-II. Madrid: CSIC.

»Perez, B. (2007). Inquisition, Pouvoir, Société. La province de Séville et ses judéoconvers sous les Rois Catholiques. París: Honoré Champion.

» Pérez, J. (1993). Historia de una tragedia. La expulsión de los judíos de España. Barcelona: Crítica.

»Pulido Serrano, J. (2002). Injurias a Cristo. Religión, política y antijudaísmo en el siglo XVII. Alcalá de Henares: Universidad de Alcalá.

» Rábade Obradó, M. (1999). La instrucción cristiana de los conversos en la Castilla del siglo XV. En la España Medieval, 22, 369-393.

» Révah, I. S. (1995). Des marranes a Spinoza. París: Librairie Philosophique J. Vrin.

» Roth, C. (1990 [1932]). Histoire des marranes. París: Éditions Liana Levi. 
»Ruiz Taboada, A. (2009). La necrópolis medieval del Cerro de la Horca. Sefarad, 69(1), 25-41.

»Ruiz Taboada, A. (2014). El cementerio judío en el contexto funerario del Toledo bajomedieval. En Passini, J. e Izquierdo Benito, R. (Eds.), La judería de Toledo: un tiempo y un espacio por rehabilitar (209-246). Cuenca: Universidad de Castilla-La Mancha.

» Ruiz Taboada, A. (2016). El límite sur de la necrópolis medieval judía del Cerro de la Horca (Toledo) y el problema del contacto con otros cementerios. Sefarad, 76(1), 121-157.

»Suárez Bilbao, F. (200o). El fuero judiego en la España cristiana. Las fuentes jurídicas. Siglos V-XV. Madrid: Dykinson.

»Suárez Fernández, L. (1964). Documentos acerca de la expulsión de los judíos. Valladolid: CSIC.

»Suárez Fernández, L. (1980). Judíos españoles en la Edad Media. Madrid: Rialp.

»Wachtel, N. (2001). La foi du souvenir. Labyrinthes marranes. París: Éditions du Seuil.

» Yerushalmi, Y. (1998). Sefardica. Essais sur l'histoire des juifs, des marranes et des nouveaux-chrétiens d'origine hispano-portugaise. París: Chandeigne. 